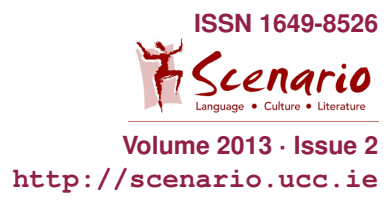

\title{
Shakespeare in Styria
}

\author{
Sean Aita
}

\begin{abstract}
This paper offers a professional theatre practitioner's reflections on directing learners between ages of 16 and 21, and whose first language is not English, in a production of Shakespeare's Twelfth Night in Murau, Austria, in July 2011. Drawing on links between the theatrical rehearsal and production process and John Biggs' 3P learning model the author argues in support of performative approaches to L2 study. Suggesting that Shakespeare's dramaturgy provides uniquely rich and varied pedagogical resources for the L2 learner, the paper presents a case for the use of theatrical performance by students as an element of ESL study.
\end{abstract}

\section{Introduction}

The production and performance of Shakespeare's plays within multicultural and multilingual contexts is by no means a new concept, and the resultant hybridity of forms have been widely discussed in a range of forums. Productions which either meld performance techniques from different cultures or use a mixture of languages to add new resonances to familiar narratives have become familiar ${ }^{1}$ to audiences around the world. However, few intercultural projects risk the challenge of expecting participants whose first language is not English, to learn and perform the text in its original form. Yet this is precisely the problem that English theatre director Nicholas Allen and Austrian designer Rudolph Wojta set themselves by founding European Shakespeare Days - Shakespeare in Styria (SIS) in 2002. Their intention was to "... bring together young actors, acting students and school leavers who intend to make theatre their career for two weeks during July each year in Murau, a tiny but beautiful medieval town tucked away in the heart of the Styrian Alps of Austria" (SIS website, see European Shakespeare Days), and then to have them rehearse and perform in a full-length play by William Shakespeare.

Within the field of ESL learning there has been much debate relating to the benefit of studying literature not least because it is considered to be "far

\footnotetext{
${ }^{1}$ Examples include the Footsbarn Travelling Theatre's multilingual summer project based on The Tempest and Youth Bridge Global's celebrated bilingual Romeo and Juliet in Mostar. http://ybglobal.org
} 
removed from the utterances of daily communication" (Collie \& Slater 2008: 2 ). Those who advocate its use, generally at an advanced level, consider its value to be in the emerging historical and social issues, which can provide fertile grounds for classroom conversation. ${ }^{2}$

The use of classical literature and particularly Shakespeare's texts, which differ radically from contemporary modes of speech, present challenges to the L2 classroom but as Cheng \& Winston (2011: 549) contend, Shakespeare's plays can provide "the kind of content that ESL curricula have neglected." The approach to dramatic literature (including Shakespeare) in the majority of ESL classrooms is to read the plays, rather than present them in a performance. The recent thematic focus of Research in Drama Education on second language learning, and publications like the University College Cork's online journal Scenario have helped to develop awareness of, and advance the debate relating to performative approaches to teaching and learning within the field. Schewe's (2013: 1) proposal of a model of Performative Fremdsprachendidaktik (Performative Foreign Languages Didactics) in Scenario is a particularly welcome addition to this field of study. In spite of these developments in the use of drama pedagogy in the L2 classroom opportunities for ESL students to participate in fully staged intercultural theatre performances using the target language are extremely rare, and therefore merit closer investigation. Using the 2011 (SIS) production of Twelfth Night as a model of practice the author argues that the rehearsal and public performance of full-length L2 theatrical texts within an ESL setting can offer an extremely effective way of enhancing language learning. The SIS students' responses to the programme presented within this paper additionally provides evidence to support the assertion that Shakespeare's plays can offer uniquely rich and varied pedagogical resources for the L2 learner.

\section{Context and Framing}

The SIS project was first established in 2002, the summer following the European Year of Languages. Its location within the Alpine-Adriatic-Danube region ${ }^{3}$ lends it a broader significance than its small-scale rural context might suggest. Led by a team of professional theatre practitioners, language teachers, and movement specialists, the programme consists of a ten-day intensive rehearsal period, and ends with three public performances of a full-length Shakespeare play in English for an audience primarily comprised of Austrian citizens. Born in the shadow of political advances by the far right Austrian Freedom Party (FPO) on a platform of anti-immigration and anti-Europeanism Allen and Wotja's project is unashamedly focused on European integration and collaboration, and offers a particular emphasis on participation from EU 'accession' nations.

Although not specifically created as an ESL programme, the practical requirements of the SIS project (presenting a Shakespeare play in English within

\footnotetext{
${ }^{2}$ For a full discussion of this issue please see McKay, Sandra (1982).
} 
set time constraints) are, from a linguistic standpoint, extremely demanding. Students have to learn a lot of new vocabulary, tackle Shakespeare's sometimes almost impenetrable rhetoric, and deal with unfamiliar and often archaic syntax in order to present their roles effectively on stage. That, generally speaking, they manage to achieve this relies upon a range of factors which will be analysed in more detail.

As a location for the project, the remote community of Murau provides a liminal space in a rural setting without the distractions of a city nightlife. In common with language immersion camps in the United States and elsewhere all interactions take place in English. Participants are assigned accommodations, and share dinner tables with nationalities other than their own to foster a strong and integrated group identity.

\section{Research overview and methodology}

My research is situated firmly within my practice as a theatre director working in community and educational settings. Over the past twenty-five years as a writer, adaptor and director for Vienna's English Theatre I have been involved in the process of making dramaturgical choices, placing language within a theatrical and cultural frame, and presenting it as a living performance in a pedagogical setting. ${ }^{5}$ My engagement as a participant within the locus of my study has, out of necessity, caused my research methodology to be primarily reliant upon the "attribution of value based on unfolding action and experience" (Barrett \& Boult 2007: 162) and upon reflective evaluation after the event. Whilst acknowledging that the research data I obtain will always be filtered through my "internal frame of reference" (Moustakas, 1990: 26). I would suggest that whatever methodology a practical researcher chooses to apply, the 'observer effect' is inevitable, and in heuristic terms quite welcome. On the other hand, 'observer bias' is a very real danger for a theatre director analysing the effectiveness of dramatic tools in the delivery of learning outcomes. I should declare at the outset then that, paradoxically, when I joined the SIS project as a guest director, I had serious doubts that a group of young people between the ages of 16 and 21, whose first language was not English, could understand, memorize, or engage with a Shakespearean text to any great degree, let alone interpret one effectively on stage. This view was enhanced by the fact that no specifically defined ESL qualifications or levels are required for students to take part in the project. ${ }^{6}$ It was only following extensive conversations with the project's production team that I began to develop a degree of confidence that this outcome might be possible and began to wonder what conditions might support this achievement.

My research question therefore addresses two specific areas of inquiry; the first relating to processes and delivery mechanisms and the second, potential applications of this method to classroom teaching. I will first speak to the

\footnotetext{
5 See Aita 2010 and 2009.
} 
processes and delivery mechanisms. Driven by my own awareness of the difficulties created by the project's parameters, I wanted to observe and record how the tools and protocols used by the project might support the acquisition, comprehension and interpretation of the language used within a Shakespearean text by participants whose L1 is other than English. Secondly, I wanted to identify what applications, if any, this process might have for the L2 classroom.

As a theatre practitioner who has used theatre as a tool for learning throughout my career, I have felt for some time that the theatrical production process resembles John Biggs' (2003: 18) 3P model of learning. Biggs suggests that what he describes as the Presage, Process and Product elements of the learning environment strongly influence learning outcomes. He emphasizes the importance of their interdependence and the alignment of these three phases. Within the theatrical production process there are also three clear stages of development, Pre Production, Rehearsal, and Performance which can be mapped to Biggs' model. I have used this framing device to describe the activities undertaken by the SIS students and staff throughout the rest of this paper to demonstrate the way in which performance-making can be seen as a learning process.

\begin{tabular}{|l|l|}
\hline BIGGS & THEATRE \\
\hline $\begin{array}{l}\text { PRESAGE Before learning takes place } \\
\text { Variables: Student motivation; prior } \\
\text { knowledge; skill; advanced preparation } \\
\text { etc. }\end{array}$ & $\begin{array}{l}\text { PRE-PRODUCTION Before production } \\
\text { takes place Tasks: Casting; text, period, } \\
\text { and character study by actor in advance } \\
\text { of rehearsal; line-learning. }\end{array}$ \\
\hline $\begin{array}{l}\text { PROCESS The actual activities } \\
\text { undertaken to facilitate learning } \\
\text { Variables: Content of the programme of } \\
\text { learning; skills of teacher. }\end{array}$ & $\begin{array}{l}\text { REHEARSAL The actual activities } \\
\text { undertaken to deliver the performance } \\
\text { Tasks: Rehearsal; character } \\
\text { development; blocking and staging; } \\
\text { scene interpretation; skills of director and } \\
\text { actors. }\end{array}$ \\
\hline $\begin{array}{l}\text { PRODUCT The outcome of learning, and } \\
\text { assessment mechanisms. Variables: } \\
\text { The goal and results of learning; method } \\
\text { of assessment; legacy - retention of } \\
\text { knowledge. }\end{array}$ & $\begin{array}{l}\text { PERFORMANCE The final outcome of } \\
\text { the rehearsal process, and the audience } \\
\text { response. Tasks: Presentation to a } \\
\text { public audience, further development of } \\
\text { role/character, demonstration of skills } \\
\text { and knowledge. }\end{array}$ \\
\hline
\end{tabular}

\section{Presage / Pre-Production}

Participants in the Shakespeare in Styria project are drawn from partnerships with schools, universities, and specialist drama academies across Europe, ${ }^{7}$ and are either currently in training or aspire to train as professional actors and stage

\footnotetext{
${ }^{7}$ Partner academies include The Academy of Theatre, Radio, Film and Television, Ljubliana; Theaterschule Bruneck, Fondazione Atlantide Teatro Stabile di Verona; The Academy of Performing Arts Bratislava; DAMU Prague; Janacek Academy of Music and Performing Arts, Brno; Luben Groys Academy, Sofia; The A cademy of D ramatic A rt, Z agreb; U niversity of the Arts, Belgrade; KUG Graz; Faculty of Dramatic Arts, Skropje; The Arts University at Bournemouth.
} 
managers. Selection takes place through an audition/interview or workshop processes. Whilst participants have differing English language skills, they share a passion for theatre/performance and have significant acting experience.

\section{Motivation}

Motivation is "one of the main determinants of second/foreign language (L2) learning achievement" (Dornyei 1994: 117) and the opportunity presented by SIS to attend a free summer programme ${ }^{8}$ in a picturesque village in the Austrian Alps provides participants with a remarkably strong extrinsic incentive to focus on their English language skills. This effect is enhanced by the appeal of living and working alongside a group of people who have common aims and interests. In a group E-mail via Facebook (Sept $\left.21^{\text {st }}, 2011\right)^{9}$ Romanian participant Cosmo reported on his experience stating that "it is special whenever people from different places and various cultures get together to do something they love the most." The significance of Cosmo's comment relating to the participants shared love of acting, cannot be underestimated. Participants Milica and Nikolo, when asked what had made them want to join the project, also emphasized the effect of the activity on them as performing artists. Nikolo identifies "meeting people from different countries, different cultures, with different characters" as being "very important for acting." while Milica points out that "by mixing cultures you mix a lot of things which are so useful to be absorbed by an actor."

The wish to develop skills within their particular art form provides an intrinsic motivational factor for some of SIS's student actors, but the desire to develop linguistically also features strongly in their responses. For participant Josef "the chance to improve my English skills and pronunciation" was a motivating factor, while others focused on the importance of being given the chance to use the English language within a performance context. For Austrian participant Franziska the appeal of SIS was in the chance to "have more fun with a foreign language; to play with the words" whilst Nikolo, a Macedonian participant, commented on "how wonderful it is to perform it [Shakespeare] in English not only to read it" adding that, "not a lot of non-English speakers have the opportunity to perform it in its original form." Franziska agrees that the chance to tackle the "old original language in the performance" was central to her desire to take part in the project. One reason which might help explain the willingness of SIS participants to engage with Shakespearean English can be found in Serbian participant Milica's belief that an intimate knowledge of Shakespeare is "very important for the actor." Milica points towards authenticity of language as a key issue, stating that, for her, the "real meaning of Shakespeare" is something one can only "see, hear, and understand in the original language."

\footnotetext{
${ }^{8}$ Accommodation and travel for all participants is provided by Shakespeare in Styria to ensure attendance is not blocked by financial constraint.

${ }^{9}$ Unless otherwise stated, all student comments are drawn from the same Facebook E-mail conversation (Sept $21^{\text {st }}, 2011$ ).
} 


\section{Prior Knowledge of English}

As previously stated, no formalESLqualifications are required of SIS participants, although interviews by SIS staff ascertain general levels of comprehension and spoken English. The outcome of this choice is a wide range of linguistic abilities amongst participants. Franziska highlights a common issue relating to extant linguistic competencies by noting that, although she had used English within a classroom context "it was the first time in my life that I played [acted] in English." This is a common experience for the majority of those taking part, and strategies for dealing with this challenge must be addressed. For Franziska the solution comes from finding an emotional connection with the language, rather than possessing an academic understanding of it, "particularly when you don't practice from time to time - like me." She identifies two ways in which she believes it is possible to engage fully with the project linguistically. The first requires a degree of technical "proficiency" in English, but the second, which she clearly applies to herself, depends upon being "really passionate about the language as a melody, and the words or the acoustic colour."

In an interview, undertaken in person with the author on July $21^{\text {st }}, 2011$ Artistic Director Nicholas Allen asserts that this "sensitivity to the aural and oral impact of language," that the best actors demonstrate, defines what most of the participants share in terms of linguist presage and helps to explain his seemingly counter-intuitive attitude to formal ESL qualifications, since bare test results cannot easily capture this delicate quality. Allen also points out that he has never encountered a situation in which a participant has misjudged his/her own linguistic potential and that, once engaged within the project, participants have always been able to achieve a positive outcome (learning the text by heart, speaking it comprehensibly, and interpreting it competently in performance).

\section{Textual Preparation}

Once selected for the programme student SIS participants are expected to undertake the same level of individual research and preparatory work on the text which would be required from professional actors. Prior to the rehearsal period, the student actors are asked to read the play they will be working on in translation, and to review commentaries in their own languages to ensure they have a grasp of the overall meaning of the scenes they will encounter. Although for Allen this can present drawbacks, as "translations can vary drastically in quality, and particularly in the German-speaking world, editors or dramaturges sometimes reassign lines to different roles, or change the order of scenes to emphasize a particular interpretation of the play" (person-to-person interview July $21^{\text {st }}, 2011$ ).

Issues of authenticity, touched on briefly in the p revious s ection covering motivation, also appear important to participants who instinctively feel that translations cannot capture the essential qualities contained within the original. SIS students Nikolo and Daniel comment that "most of the time, because of 
the translation, you could misinterpret or project something else" and that "Shakespeare in Macedonian and in English is not the same, a lot of things get lost in the translation."

Once participants have achieved a basic understanding of the play, they are asked to familiarize themselves with the English version. ${ }^{10}$ Though Allen has no hard and fast rules about memorizing text prior to rehearsal, Franziska identifies "a good preparation" as "learning the whole of the lines" in advance, describing this as "essential." The majority of participants arrive with a basic knowledge of the play and a good level of familiarity with the English text they are all required to take part in a group 'read-through' of the whole piece on the opening night of the SIS programme.

\section{Process / Rehearsal}

Intensive rehearsals at SIS take place over a two-week period beginning early in the morning and finishing half an hour before the evening meal.

Each day at SIS begins with exercises designed to support collaborative working and the ensemble's group identity. Games playing, along with physical and vocal calisthenics exercises are led by staff and students and last for approximately one hour each morning. While the director and a small group of actors work on a scene in the main rehearsal room, the remaining performers work in pairs or in small groups practicing scenes which have already been 'blocked' (worked through physically onstage with the director). The need for the student actors to develop their characters, and to motivate their actions makes the rehearsal room the locus for questions of social ontology. Discussions of authority, gender, institutions, race, customs, identity, wealth, status, and convention are an essential part of working on almost any scene from Shakespeare. During the production of Twelfth Night SIS students regularly found themselves obliged to debate complex philosophical, and cultural issues using their L2 language. Fortunately the students did not appear to view this as a particularly onerous task. Actor Daniel observes in an interview with the author (July 19 ${ }^{\text {th }}, 2011$ ) that while "it's hard to talk about the character and world [of the play] in English", it is also "really interesting because every day you want to find new things out about their lives."

Rehearsal discussions and discoveries about character encourage a reflective and responsive approach to language. What Frimberger (2009: 36) describes as "the relational, volatile and non-packageable aspects of foreign languages" which "require more creative approaches" can be addressed directly through this investigative process. The students want to communicate their findings and ideas to the director, the audience and their peers. Rather than treating

\footnotetext{
10 Texts used for the 2011 production of Twelfth Night came from Opensource Shakespeare online and were edited by the director from 2,623 lines to approximately 2,200 corresponding to roughly two hours and fifteen minutes of playing t ime. The majority of textual excisions, made primarily to aid comprehension and performability, were drawn from sections of 'humorous' word-play in scenes involving Feste, Sir Toby Belch and Sir Andrew Aguecheek.
} 
the culture of the target language as the supportive element so often described as background studies, instead we find w ithin a theatrical $r$ ehearsal process that culture and language are joined symbiotically through the feedback loop linking who the character is, to what the character says or does.

What distinguishes the way actors engage with dramatic text is that they see it as a tool for demonstrating and evidencing a character. The text is something to be spoken aloud, something to be interpreted through the voice and through the body. This means that, for the actor, rehearsal discussions lead directly to actions. Actors search for ways to present language physically, to embody it. Gestures, bits of business (activities developed by the actor and/or director to enhance the realism of stage action) and physical staged movements are combined by the actor with the words of the text to produce a richly nuanced act of communication. Research conducted by psychologist Helga Noice suggests that this kinaesthetic engagement may have a direct effect on the SIS students' memories, offering some explanation for their ability to acquire and retain Shakespeare's language in spite of its complexity and unfamiliarity.

In an interview in Time Magazine Online, conducted by Anne Murphy Paul (2012), Noice identifies the actor's integration of voice, movement and gesture as forming "a kind of bodily mnemonic device." Performers interviewed by Noice report sensing a "synchrony of speech and action" (ibid.), which enhances their ability to acquire and retain text. It is tempting to suggest that using the example of the actor's rehearsal process with its kinaesthetic approach may also offer the same advantages to other L2 learners in their acquisition of new vocabulary. Indeed research by Macedonia and Knösche at the Max Planck Institute for Human Cognitive and Brain Sciences in Leipzig confirms that gesture can have a positive effect on language learning ability. Based on MRI scans of the brain, Macedonia and Knösche have demonstrated that "enactment helps memory" and does so "by creating a more complex representation of the word that makes it more easily retrieved" (see New Scientist Website).

What might be referred to as the intentionality of language becomes increasingly important as rehearsals develop, since the emphasis on particular word or the choice of an inflection can be used by the skilful actor to convey a meaning which is either supportive of or contradictory with respect to the surface meaning of the text. Support for SIS students in developing these choices is provided through individual tutorials conducted by Austrian English language teacher and assistant director Elizabeth Mayer. Mayer focuses in detail on the play's text, working closely with SIS participants each evening after rehearsals and continuing until late at night. Using visual aids to reinforce her work, a process which has proved highly effective in language learning,

Mayer highlights and colour-codes words and sentences that students wish to focus on directly on her prompt-copy. As difficulties $\mathrm{w}$ ith inflection, pronunciation, or emphasis are tackled and mastered by the students, Mayer gradually erases these indicators. Although, in consultation with the director, she may occasionally recommend that a participant attend a session, Mayer's tutorials are voluntary, designed to allow students to monitor their own levels of 
achievement. Placing a sign-up sheet on the wall each evening allows students to decide for themselves what level of external support they require from her.

There is a strong ethos of independent learning, based on peer-to-peer counselling, which takes place during the rehearsal period, but is located outside the rehearsal room. Students who have made a particularly notable contribution in previous years are often invited to return, and asked to mentor those entering the process for the first time. This traditional "proctor model" (Bould, Cohen \& Sampson 2011: 3) combined with 'pairrainage,' the 'buddy system' through which students are paired and given responsibility for supporting one another both within the rehearsal environment and during private scene/text study, offers participants positive learning reinforcement. In the words of student Josef: "I didn't know what to expect, but having people around who had been here before, and knew what could be done made things much easier." This observational approach mirrors the traditional method of actor training used in the old English repertory system. Austrian SIS participant Julian explains how this approach has affected his experience of the programme, "I've gained so much by watching people perform, by observing them during rehearsals or just talking to them." Josef concurs, "I've learned a lot just by watching the others working on their characters and speeches."

Aside from the occasional soliloquy, Shakespeare's plays require constant interaction between the actors portraying the characters. Consequently, SIS students find the majority of their work preparing for performance involves duologues (scenes with two actors) or group scenes. In common with the majority of theatrical performance work, undertaking a Shakespeare play demands that scene partners need to rely upon one another. A scene cannot progress while one of its participants does not know his or her lines. It will not come fully to life unless all of the people taking part in it are equally clear about what they are saying and what they are doing. The SIS programme engenders in each individual a strong sense of responsibility to the team, driving their motivation to succeed so that they don't let the team down. It additionally helps to foster an environment in which students are willing provide support to other members who may be struggling. The majority of participants conform willingly to the unstated but implicit organizational 'norms' which are

- to learn the text promptly and accurately as soon as possible once the scene has been blocked, if not before;

- to identify one's own individual learning needs, and attend evening language tutorials as required;

- to work with one's scene partner(s) to further explore the social, historical, emotional context of the scene/play and bring these discoveries back into the rehearsal room. 


\section{Product / Performance}

The discovery within a performance of a new way of interpreting a line, or a different emotional character trajectory, can transform what might appear in the classroom to be dry, complex text; redefining its value and relevance. Reactions to, and interactions between audience and actor, or actor and actor, suggest, elicit and/or impose changes to intention, and consequently to inflection, tonality, and emphasis. Language use within a performance context, whilst reliant upon repetition (the actual lines of text remain a constant) must also be dynamic and responsive to the myriad subtle transformations which occur during a live performance. The opportunity for SIS participants to demonstrate their linguistic and performance skills in a public performance setting and to obtain the 'reward' of laughter, tears, and applause lies at the heart of their willingness to engage with such a demanding process.

SIS performances take place in non-theatre spaces, outdoors, or in an Elizabethan-period barn called the Moarhof. It is remarkably easy for the actor to see from the stage whether or not he or she has achieved the project's primary objective, which is to entertain an audience. The level of audience engagement, and their response to SIS productions can be demonstrated fairly simply by the fact that audience numbers have risen year on year since the foundation of the company. (Generally speaking one does not voluntarily pay to attend activities one cannot understand and that are not enjoyable; unless one is particularly masochistic.)

From a personal perspective, as an experienced professional director, I was surprised, given my preconceptions about the programme identified a the opening to this paper, to find that the SIS participants' freedom and flexibility in using the text on stage was of a remarkably high standard - better in some cases that some English L1 students I have worked with. One example of the ways in which SIS participants were able to play with and comment upon the "discursive formations" (Bristol 1996: 11) contained within Shakespearean dramaturgy, which are not limited to "expressing the concerns and interests of a narrowly circumscribed historical period," came at the opening of Act 4, Scene 1 of the 2011 production of Twelfth Night. ${ }^{11}$ The scene between Feste and Sebastian exemplifies the play's central c onfusions. The clown Feste attempts to waylay Sebastian and bring him to his mistress in the mistaken belief that Sebastian is the Count Orsino's 'gentleman' Cesario. During their encounter an increasingly frustrated Sebastian offers the clown money to leave him alone, finally shouting in exasperation "I prithee foolish Greek depart from me: if you tarry longer I shall give worse payment" (IV, I: 1968-1970). On the first night of the SIS performance of the play, Nikolo a young actor from the Faculty of Dramatic Arts in Skropje, playing the role of Feste, picked up the coin which had been thrown for him, paused for a beat, and then improvised a new line in response to Sebastian's insult; "I'm not Greek, I'm Macedonian!" It was an amusing aside, thrown into the performance spontaneously and, to judge by their reactions, enjoyed by the audience and the other actors onstage. Yet 
the comment was not quite as disingenuous as it might appear, since he was speaking directly towards fellow SIS participant Dimitrios, a Thessalonican actor who was standing in the opposite wing, waiting to enter as Malvolio. Although Nikolo's quip was undoubtedly a statement about his national and personal identity, he was also fully aware of the double meaning present in his comment. He was pointing out that is not necessary to be Greek to be foolish. A Macedonian can be foolish too.

\section{Conclusions and Emergent Themes}

One of the most obvious outcomes of the SIS project is that it demonstrates that engagement by L2 learners in a fully staged performance of one of Shakespeare's plays can provide an extremely positive ESL learning experience, despite the text's apparent inutility. The speed and accuracy with which SIS participants absorbed words and sentences that were often complex and unfamiliar during the rehearsal process, and their ability to not only retain, but to present this language convincingly and accurately in a public performance were impressive.

My first-hand observation of the actors' process during the production period leads me to believe that there are important implications for L2 learners to be found in the research undertaken by psychologist Helga Noice (see Paul 2012) into the relationship between the way actors memorize text and their use of movement onstage. When placed in the context of the findings of Macedonia and Knösche (see New Scientist Website), the benefits f or L 21 earners of the theatrical rehearsal and performance process in which a combination of language, movement, and gesture is integral becomes increasingly convincing. With regard to arguments against the use of literature within the L2 classroom it seems evident that the profundity of Shakespeare's dramaturgy and acuity of his character creation can allow L2 students to explore a far wider range of human experience than the majority of utilitarian classroom texts. Performing Shakespeare's words aloud on a stage seems to be the key to engaging with his language fully. Taking part in the SIS Twelfth Night transformed many of the participants' understanding of, and feelings about Shakespeare. Summing up his personal response to the SIS process, participant Julian explains that what he enjoyed most was the opportunity to "experience his [Shakespeare's] plays from a different angle, [and to] get to love him, which I never thought possible." Participant Patrizia agrees, announcing that "I see Shakespeare from a different light now."

Thematically I would identify kinaesthetic practice as being central to the SIS programme. The liminal location, task orientation (exclusive focus on performing the play), and linguistic immersion of the learning environment are all supported by motivational factors such as group identity, the shared desire to succeed, and by peer to peer learning. The exact conditions of the SIS project listed above are undoubtedly problematic to replicate within a classroom context. 


\section{Implications for the Classroom}

Elizabeth Mayer (SIS's language teaching specialist) has been inspired to take the production and performance of English drama back into her Austrian secondary school work setting at Bundesgymnasium Wien 13 by founding an English Drama Club.

In the academic year 2011/12, her students tackled Shakespeare for the first time performing a compilation of scenes and extracts from his plays entitled $\mathrm{Oh}$ no, not Shakespeare! Mayer believes that the current school system in Austria makes performance difficult to provide within the curriculum, pointing out that "you can't do drama in a rigid timetable once a week. You need to be much more flexible" (E-mail August 22 ${ }^{\text {nd }}, 2013$ ). As a result, she has been obliged to make the Drama Club an extra-curricular activity. Her students' comments (taken from the draft of the school's year book 2013/14) accord with those of the SIS participants in describing the benefits of performance as a strategy for language learning. One of her Bundesgymnasium students explains in the year book what it is that she feels working in a theatre group in a second language offers her.

Der English Drama Club bereichert mit unendlich vielen Erfahrungen und positiven Eindrücken. Man lernt nicht nur seine schauspielerischen Talente auf der Bühne umzusetzen und auszubauen, man findet sich überdies in einer Gruppe aufgeschlossener und aufgeweckter SchülerInnen wieder, die ein gemeinsames Interesse teilen und zusammen intensive Probenzeiten durchleben und sich dadurch neu entdecken und näher kommen, ohne Hinblick auf Schulklasse und Alter.

Unlike many ESL teachers, Mayer is comfortable with directing student actors and producing drama on stage. If, as it appears to be, using theatrical performance is an approach which students can benefit $f$ rom, then o ne of the first $\mathrm{t}$ hings $\mathrm{t}$ hat $\mathrm{w}$ ill $\mathrm{n}$ eed $\mathrm{t} \mathrm{o} \mathrm{b}$ e a ddressed i $\mathrm{s}$ the $\mathrm{p}$ rovision of training opportunities so that teachers can develop the requisite skills as part of their CPD.

\section{Legacy}

The retention of language acquired by SIS students taking part in Twelfth Night is not a short- term phenomenon. A group email conversation with 5 of the actors from the 2011 production on February $26^{\text {th }}, 2013$ provides evidence that almost two years after the production participants can still draw on the language they assimilated during the two weeks of the project. Cosmo states that "it's still there" [the text], and that "with a simple reading can be even better ... possibly with new colours", suggesting that he could now find deeper insights if he returned to the script again. Nikolo reports that "a lot, most, is still here in my mind," and Daniel asserts that "he remembers a lot of lines." For Franziska, the words are "still deep in my brain," and the play itself is "like a melody which I can remember." 


\section{Bibliography}

Aita, Sean (2010): "Performing England. Language and culture in performative praxis." In: Nicholson, Helen (ed.) Research in drama education (Vol. 15, Issue 3). London: Routledge, 361-384

Aita, Sean (2009): "The theatre in language learning (TILL) model. Exploring theatre as pedagogy in the L2 Environment," In: Scenario III/1, 70-89

Barrett, Estelle; Boult, Barbara (2007): Practice as research: approaches to creative arts enquiry. London: I.B. Tauris

Biggs, John (2003): Teaching for quality learning at university. Buckingham: Open University Press

Bristol, Michael (1996): Big Time Shakespeare. London: Routledge

Bould, David; Cohen, Ruth; Sampson, Jane (2001): Peer learning in higher education: learning from \& with each other. London: Routledge

Collie, Joanne; Slater, Stephen (1987): Literature in the language classroom: a resource book of ideas and activities. Cambridge: Cambridge University Press

Cheng, Astrid Yi-Mei; Winston, Joe (2011): Shakespeare as a second language: playfulness, power and pedagogy in the ESL classroom. In: Research in Drama Education: The Journal of Applied Theatre and Performance 4: 541-556

Dolati, Romana; Richard, Cameron (2011): Harnessing the use of visual learning aids in the English language classroom. In: Arab World English Journal 2/1, 3-17

Dornyei, Zoltan (1994): Motivation and motivating in the foreign language classroom. In: The Modern Language Journal 3: 273-284

European Shakespeare Days, Shakespeare in Styria. http://www. shakespeare-in-styria.org last accessed Jan $10^{\text {th }}, 2012$ )

Frimberger, Katja (2009): Towards a pedagogy of strangeness. Exploring the potential of strangeness for foreign language Education. In: Scenario III/1: 36-49

McKay, Sandra (1982): Literature in the ESL classroom. In TESOL Quarterly 16: $529-536$

Moustakas, Clark (1990): Heuristic research: design, methodology and applications. London: Sage

New Scientist (2012): Learn languages faster with gestures. In New ScientistLife. http://www.newscientist.com/article/mg21228442.800-learnlanguage-faster-with-gestures.html\#.UokYJ03FLIU (last accessed Nov $18^{\text {th }}$, 2013)

Paul, Anne M. (2012): What actors can teach us about memory and learning. In Time Ideas. http://ideas.time.com/2012/02/22/what-actors-canteach-us-about-memory-and-learning/ (last accessed Nov $18^{\text {th }}, 2013$ ) 
Schewe, Manfred (2013): Taking Stock and Looking Ahead: Drama Pedagogy as a Gateway to a Performative Teaching and Learning Culture. In: Scenario VII/1, 5-27

Staudinger, Eduard; Promitzer, Christian; Hermanik, Klaus-Jürgen (2002): Hidden minorities: Language and ethnic identities in the Alpine-Adriatic region. Strasbourg: European Science Foundation.

http://www.theslovenian.com/articles/staudinger.pdf (last accessed Nov $18^{\text {th }}, 2013$ ) 